\title{
Notions regarding the design of suction systems for industrial ventilation
}

\author{
Ion Gherghe $^{1 *}$, Doru Cioclea ${ }^{1}$, Florin Rădoi ${ }^{1}$, Adrian Matei ${ }^{1}$, and Răzvan Drăgoescu ${ }^{1}$ \\ ${ }^{1}$ National Institute for Research and Development in Mine Safety and Protection to Explosion - \\ INSEMEX, 32-34 G-ral Vasile Milea Street, Petroșani, Hunedoara, Romania
}

\begin{abstract}
Air flow in ducts is one of the basic processes of ventilation and air conditioning. Knowledge of this phenomenon and the laws according to it is indispensable for drawing up the sizing calculations of the duct networks, for determining the energy needed to move the air as well as for determining the aerodynamic parameters related to the ventilation ducts. Industrial buildings include large spaces with various sources of releases of harmful substances. Type of these sources and their location depends on the technological process in each section or room. The main role of industrial ventilation systems is to provide a continuous source of fresh air supply from the outside, to keep the temperature and humidity at comfortable levels, to maintain an adequate supply of oxygen in the work area, to control concentrations of hazardous explosive and / or toxic gases in the air and at work, to remove unwanted odors from a particular area and to remove and dilute airborne contaminants. The paper presents the design of exhaust systems, the calculation of suction ventilation systems and the choice of ducts with higher aerodynamic parameters in the choice of fans, using nomograms.
\end{abstract}

\section{Introduction}

The ventilation and air conditioning installations in the rooms aim to achieve a comfortable and hygienic environment. In the case of industrial rooms, these installations create in addition to a favorable environment for the good development of the technological process, and comfort conditions that lead to a significant increase in labor productivity.

The design and construction of an individual ventilation system must harmonize the comfort requirements with those of the management of the ventilation system by the user, without inadvertently affecting the other functions of the system.

When harmful emissions produce a defect in the room that endangers human health or affects their comfort, the use of special ventilation systems is required [1].

\footnotetext{
* Corresponding author: ion.gherghe@insemex.ro
} 


\section{Design of exhaust systems}

Designing an efficient suction system is a very complex process that involves knowing a large number of factors. Each suction port must be designed in such a way that the dust in question does not allow toxic and / or explosive gases to be recirculated, but at the same time, it becomes necessary to capture coarse particles that can clog the ventilation ducts [2].

In Table 1, shows the influence of air velocities at the end of the tubes column, as a percentage of the tube diameter, as a function of the air velocity in the center of the tube, as a percentage of the average velocity.

Table 1. The influence of air velocities.

\begin{tabular}{|c|c|}
\hline $\begin{array}{c}\text { Distances at the end of the column } \\
\text { as a percentage of its diameter }\end{array}$ & $\begin{array}{c}\text { Air velocity in the center of the tube as a } \\
\text { percentage of the average velocity at the end of the } \\
\text { column }\end{array}$ \\
\hline 25 & 57 \\
\hline 50 & 25 \\
\hline 75 & 13 \\
\hline 100 & 7 \\
\hline
\end{tabular}

The values in Table 1 are specific to the circular columns. If the air velocity at the end of a column with a diameter of $100 \mathrm{~mm}$ is $20 \mathrm{~m} / \mathrm{s}$, the suction at a distance of $100 \mathrm{~mm}$ from it (ie $100 \%$ of the diameter) will only be $7 \%$ of $20=1.4 \mathrm{~m} / \mathrm{s}$.

For this reason, the suction mouths must be designed so that the source of dust or explosive and / or toxic atmospheres is isolated as far away as possible. If the toxic / explosive atmosphere is moving rapidly, the suction mouth must be placed in the direction of its movement.

Contaminated air trapped by a suction port must be transported along the duct at such a speed as to avoid increasing the concentration of gases in the duct or depositing dust on its walls.

Considering the case where $10 \mathrm{~m}^{3} / \mathrm{s}$ are transported on a column with a length of $100 \mathrm{~m}$ at a speed of $10 \mathrm{~m} / \mathrm{s}$ and a cross section of $1 \mathrm{~m}^{2}$ is required. If a coefficient of friction of $\mathrm{K}=$ 0.003 is adopted, the results presented in Table 2 are obtained:

Table 2. Pressure losses in pipes.

\begin{tabular}{|c|c|c|c|}
\hline Size (m) & $\begin{array}{c}\text { Perimeter } \\
\mathbf{P}(\mathbf{m})\end{array}$ & $\begin{array}{c}\text { Pressure loss } \\
\mathbf{H}(\mathbf{P a})\end{array}$ & $\begin{array}{c}\text { Pressure loss as a percentage of } \\
\text { circular column loss }\end{array}$ \\
\hline 1.13 size & 3.54 & 106 & 100 \\
\hline $1 \times 1$ & 4.00 & 120 & 113 \\
\hline $1.25 \times 0.80$ & 4.10 & 123 & 116 \\
\hline $1.50 \times 0.67$ & 4.33 & 130 & 141 \\
\hline $2.00 \times 0.50$ & 5.0 & 150 & 164 \\
\hline $2.50 \times 0.40$ & 5.80 & 174 & 188 \\
\hline $3.00 \times 0.33$ & 6.67 & 200 & \\
\hline
\end{tabular}

There are tables, with the help of which the pressure losses in circular columns can be found, for different values of the air flow. These tables can also be used for rectangular columns if the equivalent diameter of the column is calculated in advance from the equation: 


$$
\text { Equivalent diameter }=4 \times \frac{\text { Surface }}{\text { Perimeter }}
$$

In the tables, this value is used in association with the air speed and not with the air flow, in order to determine the pressure losses. The reason is that a rectangular column has a much larger area than a circular one for the same equivalent diameter, consequently being able to carry a higher air flow at the same pressure loss, if the pressure losses correspond, then the air velocities are identical, after as can be seen from Table 3.

Table 3. Pressure losses that occur in ventilation columns.

\begin{tabular}{|c|c|c|c|c|c|c|}
\hline $\begin{array}{c}\text { The shape of } \\
\text { the pipe }\end{array}$ & Size (m) & $\begin{array}{c}\text { Equivalent } \\
\text { diameter } \\
\mathbf{( m )}\end{array}$ & $\begin{array}{c}\text { Speed } \\
\mathbf{V ~ ( m / s )}\end{array}$ & $\begin{array}{c}\text { Surface } \\
\mathbf{S}\left(\mathbf{m}^{\mathbf{2}}\right)\end{array}$ & $\begin{array}{c}\text { Air flow } \\
\mathbf{Q}\left(\mathbf{m}^{\mathbf{3}} / \mathbf{s}\right)\end{array}$ & $\begin{array}{c}\text { Pressure drop per } \\
\mathbf{1 0 0} \mathbf{~ m m}, \mathbf{H}(\mathbf{P a})\end{array}$ \\
\hline Circular & 1.00 & 1.00 & 15 & 0.785 & 11.8 & 270 \\
\hline Square & $1.00 \times 1.00$ & 1.00 & 15 & 1.000 & 15.0 & 270 \\
\hline Rectangular & $2.00 \times 0.67$ & 1.00 & 15 & 1.333 & 20.0 & 270 \\
\hline
\end{tabular}

In addition to the internal resistance to air flow due to viscosity, the frictional resistance due to the friction of the air against the pipe walls, the air flow is also slowed by the presence of fillings, curves and variations in the cross section of the pipe.

Duct fillings slow down the flow of air in two ways, namely:

- First, fillings produce a reduction in the free section of the pipe which results in an increase in air velocity which, as shown by the Atkinson equation, leads to an increase in frictional resistance;

- Secondly, however, the air flow lines are interrupted by the presence of fillings producing eddy currents that lead to energy losses.

\section{Calculation of suction systems}

The calculation of any ventilation system starts from the farthest point from the fan. If a very simple suction system is taken into account, as the one represented in Figure 1 and starting from the assumption that it is necessary to aspirate a flow of $1 \mathrm{~m}^{3} / \mathrm{s}$ from point A and $0.5 \mathrm{~m}^{3} / \mathrm{s}$ each from points $\mathrm{B}$ and $\mathrm{C}$, and the minimum air transport speed is $14 \mathrm{~m} / \mathrm{s}$, the falls The column inlet pressure is $78 \mathrm{~Pa}$ in dynamic pressure in $\mathrm{A}, 29 \mathrm{~Pa}$ in $\mathrm{B}$ and $49 \mathrm{~Pa}$ in C. [2].

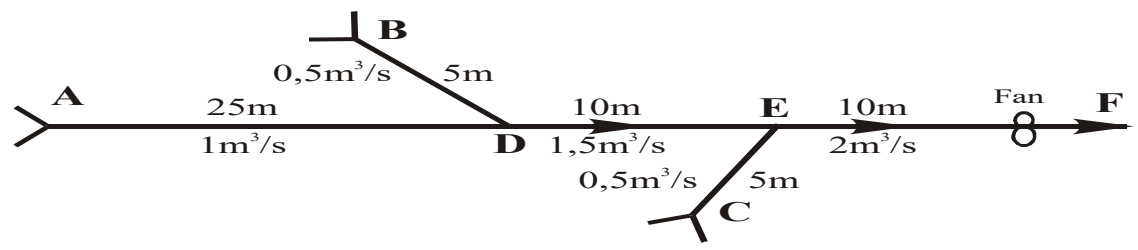

Fig. 1. Branched suction system.

The approximate pipe dimensions for the specified speeds and volume shall have diameters of $300 \mathrm{~mm}$ from point $\mathrm{A}$ to point $\mathrm{D}, 200 \mathrm{~mm}$ for the $\mathrm{BD}$ and CE branches, 360 $\mathrm{mm}$ for the DE pipe and $400 \mathrm{~mm}$ for the EF pipe.

For a flow of $1 \mathrm{~m}^{3} / \mathrm{s}$, on a pipe with a diameter of $300 \mathrm{~mm}$ between the points $\mathrm{AD}$ the air speed will be $14.15 \mathrm{~m} / \mathrm{s}$, which corresponds to a dynamic pressure (at sea density) of $118 \mathrm{~Pa}$. The pressure drop at the inlet to point A will be:

$$
\mathrm{Ha}=78 / 100 \times 118=92 \mathrm{~Pa}
$$


The negative static pressure in the pipe near point A will thus be $118+92=210 \mathrm{~Pa}$. The pressure loss in a $300 \mathrm{~mm}$ pipe carrying $1 \mathrm{~m}^{3} / \mathrm{s}$ of air is $78 \mathrm{~Pa}$ per 100 meters and therefore on 25 meters we will have:

$$
25 \mathrm{mx} 78 / 100=20 \mathrm{~Pa}
$$

The negative static pressure at $\mathrm{D}$ will thus be $210+20=230 \mathrm{~Pa}$.

The BD branch can be calculated in exactly the same way to require a negative static pressure of $153.5 \mathrm{~Pa}$, for a flow rate of $0.5 \mathrm{~m}^{3} / \mathrm{s}$. But the pressure at $\mathrm{D}$ is $230 \mathrm{~Pa}$. Therefore, the volume of air that will actually flow through the $200 \mathrm{~mm}$ pipe corresponding to the BD branch will not be $0.5 \mathrm{~m}^{3} / \mathrm{s}$ :

$$
0,5 \mathrm{x} \sqrt{\frac{230}{153,5}}=0,61 \mathrm{~m}^{3} / \mathrm{s} \text { for a speed of } 19,5 \mathrm{~m} / \mathrm{s}
$$

This is too much and will increase the fan parameters and costs.

The recalculation will be made for a pipe of $180 \mathrm{~mm}$ on the BD branch instead of 200 $\mathrm{mm}$, resulting in an air volume of $0.49 \mathrm{~m}^{3} / \mathrm{s}$, and an air speed of $19.3 \mathrm{~m} / \mathrm{s}$. Although this speed is very high and will lead to increased abrasion in this branch, this alternative is preferable to using a $200 \mathrm{~mm}$ pipe.

On the DE branch the flow will be $1.49 \mathrm{~m}^{3} / \mathrm{s}$. The pressure loss along $10 \mathrm{~m}$ of pipe with a diameter of $360 \mathrm{~mm}$ will be $77 \mathrm{~Pa}$, and the suction at $\mathrm{E}$ will be $230+77=307 \mathrm{~Pa}$.

Having the data for the $\mathrm{BD}$ branch, the $180 \mathrm{~mm}$ pipe will now be considered for the $\mathrm{CE}$ branch as well. The calculation shows that a depression of $307 \mathrm{~Pa}$ will aspire to a flow rate of $0.51 \mathrm{~m}^{3} / \mathrm{s}$, thereby with a speed of $19.8 \mathrm{~m} / \mathrm{s}$

The pressure drop on the $400 \mathrm{~mm}$ column related to the EF branch for a flow rate of 2.0 $\mathrm{m}^{3} / \mathrm{s}$, will be $75 \mathrm{~Pa}$ with an air speed of $15.9 \mathrm{~m} / \mathrm{s}$. Therefore, the fan must be able to supply a negative static pressure on the suction side of $307 \pm 75=382 \mathrm{~Pa}$ when circulating 2,00 $\mathrm{m}^{3} / \mathrm{s}$. The pressure on the discharge side will depend on the design of the pipe and the filter on that side.

In this example a real problem arose, solving this case leads to considerations regarding both the appropriateness of mounting the fan near point $\mathrm{D}$ instead of point $\mathrm{F}$ because it is centrally located and reduces the need for air and column leakage losses (point A).

An elbow at $90^{\circ}$ in a column of tubes has a much greater strength than the equivalent length of the straight column. Its actual strength depends mainly on the angle of the elbow, which is usually expressed as the ratio of the rays. The radius ratio is defined as the ratio between the average radius of the elbow and the diameter of the column, where the average radius is the inner radius plus half the diameter of the pipe.

In Figure 2, R1 is the outer radius, R2 is the middle radius and R3 is the inner radius. The ratio of the rays is therefore $R_{2} / D$. The ratio of the rays is therefore. A radius ratio of two or more indicates a smooth elbow while a smaller value indicates an elbow with a small connection angle, as shown in Table 4.

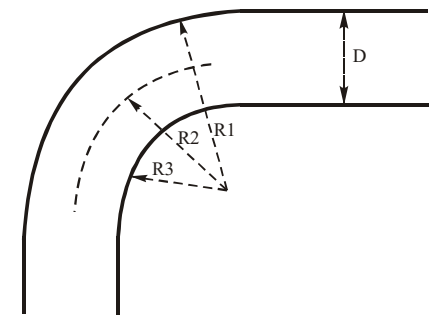

Fig. 2. Elbow at $90^{\circ}$. 
Table 4. Equivalent resistances.

\begin{tabular}{|c|c|}
\hline Radius ratio & Straight column length with resistance equivalent to $\mathbf{9 0}^{\circ}$ elbow \\
\hline 0.5 & $48 \mathrm{D}$ \\
\hline 1.0 & $18 \mathrm{D}$ \\
\hline 2.0 & $11 \mathrm{D}$ \\
\hline
\end{tabular}

The pressure drop at an elbow of $45^{\circ}$ represents $50 \%$ of that of an elbow of $90^{\circ}$. If, in fig. no.2, column $\mathrm{AD}$ would have two elbows at $90^{\circ}$ and one at $60^{\circ}$ with a radius ratio of 2.0 for the purpose of calculations, its length should be $25+(11+11+7) \times 0.3=33.7$. In order to minimize both pressure losses and friction, it is desirable to use as few bends as possible when designing the suction systems (Figure 3).
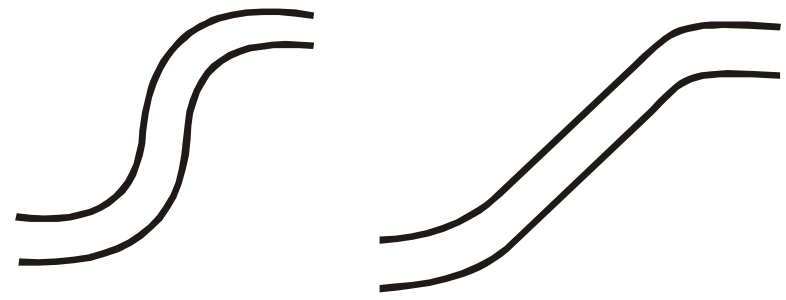

Fig. 3. (a) Elbows at $90^{\circ}$; (b) Elbows at $45^{\circ}$.

In Figure 3 a) two bends at $90^{\circ}$ are used in order to join two columns located at different levels. In Figure $3 \mathrm{~b}$ ) the same result can be obtained with the help of two elbows at $45^{\circ}$ situation in which the resistance is reduced by half. In the case of an elbow in a rectangular column there is an additional factor that affects the pressure loss, namely the shape coefficient. This factor is defined as the ratio between its width and height. A square column has a shape coefficient $=1$. A wide elbow with a wide width has a high shape coefficient ( 2 or more) which leads to low pressure losses. A narrow elbow has a low coefficient of shape ( 0.5 or less) and is characterized by high pressure losses.

The branch should enter the conical portion at an angle of $45^{\circ}$ or even smaller, preferably $30^{\circ}$. The air velocities in the branch and in the main column, upstream and downstream of the connection, must be as identical as possible.

\section{Ventilation ducts with superior aerodynamic parameters}

When air flows through a ventilation column, the pressure required to push or suck air through it depends not only on the internal friction force but also on the dimensions, length and shape of the pipe, the roughness of its walls, the nature of the obstructions inside, air speed and density.

Air leaks in both the main and secondary columns are another source of air leaks. Factors that amplify losses are:

* Location of fans;

* Diameter and length of the column;

* Pressure drop and column condition.

In design, the largest possible diameter must be chosen from a practical point of view. 


\subsection{Column types with higher parameters}

The air ducts must be made of materials with the lowest possible roughness and which make it possible to achieve tight constructions. The materials used for the air ducts must be non-combustible, especially in cases where the ducts pass through several rooms and through which toxic and / or explosive gases are conveyed.

The pipes with the highest transport capacity $\left(\mathrm{m}^{3} / \mathrm{h}\right.$ air) are round or square, and for those with a rectangular section, aspect ratios greater than 8: 1 must be avoided. It is recommended that the value of these ratios be as small as possible, and in current applications, at most 4:1. [1].

The amount of air flowing through a duct depends on the cross-sectional area (duct opening area) and air velocity. Air that moves too slowly will allow contaminants, such as dust, to deposit and accumulate, and these particles will eventually clog the pipe. Air that carries heavy dust particles too quickly can cause noise problems and cause excessive duct abrasion. [3-5]

\subsection{Types of pipes used in industrial ventilation}

There are several types of pipes made of different materials and having the following constructional characteristics [5]:

a) Metal tubes:

$>$ The lowest investment costs for the aspiring columns;

$>$ They are not flammable;

$>$ Allow the application of positive and negative pressure;

$>$ Air losses through medium columns and low friction;

$>$ They allow a single use if they are hit, especially at the ends of the column where the joint is made, in order not to increase the flow of recirculated air in the pipe.

b) Fiberglass tubes:

$>$ Suction columns much more durable, flame resistant;

$>$ Durability in different conditions and low weight;

$>$ Allow the application of positive and negative pressure;

$>$ Reduced air friction coefficient of the column walls;

$>$ Can be reused;

c) Suction hoses:

$>$ They are flame resistant;

$>$ Possibility of increasing the restriction of the length of the column in the tubes;

$>$ The weight of the piping depends on the size of the depression that is exerted on the ventilation pipe;

$>$ They can be stored in small spaces;

$>$ It is applied for short column length and can be connected with other types of ventilation columns.

d) Smooth ventilation columns (without metal fittings):

$>$ They have low cost, flame resistant and low air losses for long column lengths;

$>$ The size of the pressure on the flexible column is dependent on the type of material and the way of realization;

$>$ Average value of the coefficient of friction; 


\subsection{Calculation of losses in ventilation columns}

There are two types of air leaks through a ventilation duct, namely: dynamic pressure losses and friction losses [1-3].

The pressure drop at each inlet, outlet and outlet must be calculated individually, this being based on the dynamic air pressure at that point in the system.

The dynamic air pressure is given by the relation:

$$
\mathrm{P}_{\mathrm{d}}=\mathrm{P}_{\mathrm{t}}-\mathrm{P}_{\mathrm{s}} \quad(\mathrm{Pa})
$$

The pressure drop in a pipe is given by Atkinson's equation:

$$
\mathrm{P}=\frac{\alpha L P_{e}}{S^{3}} x Q^{2}
$$

Since this relation is valid only for the standard air density ( $\rho s t=1.2 \mathrm{~kg} / \mathrm{m}^{3}$ ), for the generalization of this relation and for other values of the air density, this relation becomes:

$$
\mathrm{P}=\frac{\alpha_{1,2} L P_{e}}{S^{3}} x Q^{2} x \frac{\rho}{1,2}
$$

For all relationships, the definitions are:

○ $\mathrm{P}_{\mathrm{d}}$ - dynamic pressure in the column, in $\mathrm{Pa}$;

- $\mathrm{P}_{\mathrm{st}}$ - static pressure, in $\mathrm{Pa}$;

- $\mathrm{P}_{\mathrm{t}}$ - total pressure, in $\mathrm{Pa}$;

○ $\quad \alpha$-aerodynamic friction coefficient, dependent on air density, in $\mathrm{kg} / \mathrm{m}^{3}$;

- L - length, in $\mathrm{m}$;

- $\mathrm{P}_{\mathrm{e}}-$ the perimeter, in $\mathrm{m}$;

- $\mathrm{S}$ - pipe section, in $\mathrm{m}^{2}$;

- Q - air flow, in $\mathrm{m}^{3} / \mathrm{s}$;

- $\rho$ - air density for standard conditions, in $\mathrm{kg} / \mathrm{m}^{3}$;

In Figures 4 and 5, presents the nomograms for assessing the aerodynamic parameters for rigid columns made of glass and metal fibers (with applicability only in the case of exhaust systems).

\section{Evaluation of fan curves and pressure loss curves}

To determine the friction losses, proceed as follows (according to the diagram in Figure 4) $[4,5]$ :

$>$ the average air flow from the column is determined (air at the work front $+1 / 2$ losses due to leaks);

$>$ follow the line corresponding to the diameter of the column we want to analyze, and read on the axis the static pressure drop / $30 \mathrm{~m}$;

$>$ multiply this figure obtained by the length of the column to obtain the friction losses.

For example, $800 \mathrm{~m}^{3} / \mathrm{min}$ are required, the length of the flexible discharge column is $600 \mathrm{~m}$ and the diameter is $900 \mathrm{~mm}$ and the leakage losses are $115 \mathrm{~m}^{3} / \mathrm{min}$. 


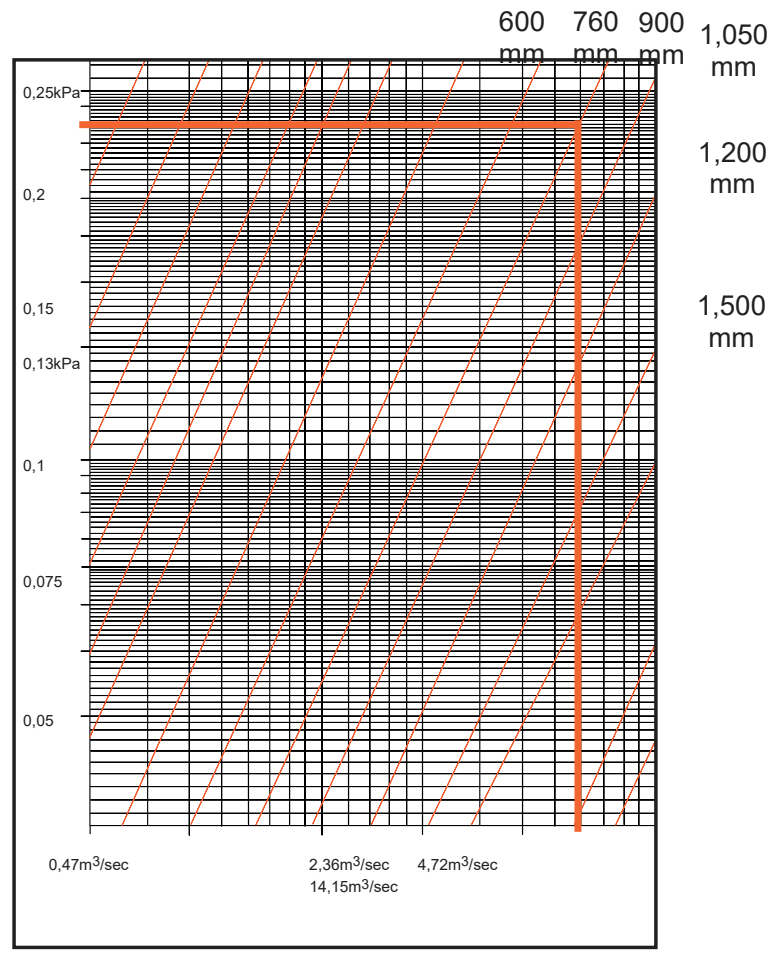

Fig. 4. Nomogram for determining friction losses through pipes.

The average air flow in the column will be $850 \mathrm{~m}^{3} / \mathrm{min}$, resulting in a pressure loss of 20 $\mathrm{daPa} / 30 \mathrm{~m}$ or $400 \mathrm{daPa}$ in total.

For the choice of the fan (Figure 5) it starts from the total pressure, and at the intersection of its afferent line with the vertical raised near the value of the air flow, it is evaluated if the intersection point is above or below the fan curve.

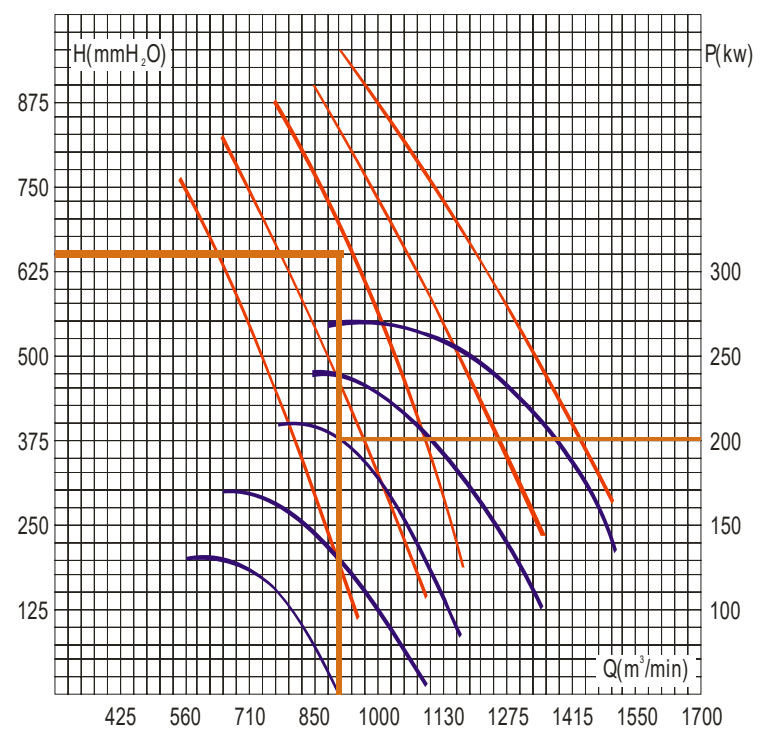

Fig. 5. Diagram and how to choose the fan. 
In order to obtain the required total pressure at the fan level, friction losses, dynamic losses and dynamic pressure are added.

According to the figure below if the dynamic losses have the value of $200 \mathrm{mmH}_{2} \mathrm{O}$ and the dynamic pressure is $32 \mathrm{mmH}_{2} \mathrm{O}$ we will have a total pressure loss of $640 \mathrm{mmH}_{2} \mathrm{O}$ and a fan air flow of $900 \mathrm{~m}^{3} / \mathrm{min}$. Consequently, from the fan diagrams, it can be seen that the use of a fan with a diameter of $800 \mathrm{~mm}$ satisfies the requirements, and the increase in the diameter of a vent column results in a significant reduction in the pressure drop.

The suction columns also allow the air to be filtered, which is an advantage in terms of dust control, especially where the serial placement of the fans is practiced. The disadvantages are the initial costs, the need to provide electricity to the fans, the provision of space for the ventilation columns and the noise produced by the fans.

Particular care must be taken to ensure that the pressure-flow characteristics of the fans take into account the strength of the column. The strength of the column is established as a combination of frictional losses of the inner walls of the pipe, frontal losses at any curve or change of cross section and those that occur at the end of the column.

For example:

$>$ A flow of $15 \mathrm{~m}^{3} / \mathrm{s}$ must be conveyed through a fiberglass column with a diameter of $0.9 \mathrm{~m}$, length of $200 \mathrm{~m}$, and which has an elbow at $90^{\circ}$.

From the technical literature, the friction coefficient for the column is $0.0032 \mathrm{~kg} / \mathrm{m}^{3}$. The total pressure to be developed by the fan and the power to be developed must be calculated, knowing that $\eta=60 \%$ and $\rho=1.2 \mathrm{~kg} / \mathrm{m}^{3}$.

$>$ Solution: - pipe section $\mathrm{A}=\pi \times 0.92 / 4=0.636 \mathrm{~m}^{2}$; - the perimeter $\mathrm{P}=\pi \times 0.9=2.827 \mathrm{~m}$.

$>$ The coefficient of pressure loss by friction of the system is determined;

$>$ At input, in the absence of any input adjustment, the coefficient of friction loss is, Xint $=1.0$.

It is produced by the turbulence with which air enters the column and should not be confused with the transformation of static pressure into dynamic inlet pressure.

For an elbow at $90^{\circ}, \mathrm{Xb}=1.2$

$>$ At the exit, Exit $=1.0$. This is not a real loss but represents the kinetic energy of the air produced by the fan and lost in the surrounding atmosphere;

$>$ Total frontal pressure coefficient: $\mathrm{X}=1.0+1.2+1.0=3.2$;

$>$ The equivalent resistance for friction pressure losses will be:

$$
\mathrm{R}_{\text {echiv. }}=\frac{X_{i e ; i r e} x \rho}{2 A^{2}}=\frac{3,2 x 1,2}{2 x(0,636)^{2}}=4,744 \quad \mathrm{Ns}^{2} / \mathrm{m}^{8}
$$

Strength of the column:

$$
\mathrm{R}_{\mathrm{c}}=\frac{\alpha L P}{S^{3}}=\frac{0,0032 \times 200 \times 2,827}{(0,636)^{3}}=7,028 \quad \mathrm{Ns}^{2} / \mathrm{m}^{8}
$$

Total strength of the column:

$$
\mathrm{R}_{\text {tot }}=\mathrm{R}_{\text {echiv }}+\mathrm{R}_{\mathrm{c}}=4,744+7,028=11,772 \quad \mathrm{Ns}^{2} / \mathrm{m}^{8}
$$

The total pressure will be:

$$
\mathrm{H}_{\mathrm{t}}=\mathrm{R}_{\mathrm{t}} \times \mathrm{Q}^{2}=11,772 \times 15,0^{2}=2649 \mathrm{~Pa}
$$

$>$ The power required for the engine at a efficiency of $60 \%$ will be: 


$$
\mathrm{P}_{\mathrm{m}}=\frac{H_{t} x Q}{\eta}=\frac{2649 \times 15}{1000 \times 0,6}=66,2 \mathrm{kw}
$$

\section{Conclusions}

Suction holes must be designed so that the source of dust or explosive and / or toxic atmospheres is isolated as far away as possible.

Contaminated air trapped by a suction port must be transported along the pipe at such a speed as to avoid increasing the concentration of gases in the duct or depositing dust on its walls.

Pipe fillings slow down the flow of air due to the reduction of the free section, the increase of the frictional resistance and the eddy currents that lead to energy losses.

The calculation of any ventilation system starts from the farthest point from the fan.

An elbow at $90^{\circ}$ in a column of tubes has a much greater strength than the equivalent length of the straight column. The pressure loss in a $45^{\circ}$ elbow represents $50 \%$ of that corresponding to a $90^{\circ}$ elbow.

The pipes with the highest transport capacity $\left(\mathrm{m}^{3} / \mathrm{h}\right.$ air) are round or square.

The amount of air flowing through a duct depends on the cross-sectional area and air velocity.

Air leaks in a ventilation duct are of two types, namely: dynamic pressure losses and friction losses.

The nomograms shown allow the choice of the diameter of the tube column according to the static pressure developed by the ventilation fans and the air flow required to be conveyed through the column.

This paper was developed within the Nucleu-Programme, carried out with the support of MCID, project no. PN 19210204.

\section{References}

1. C. Alexandru, Ventilation and air conditioning, (in Romanian), vol.I, (Technical Publishing House Bucharest, Romania, 1968)

2. W.L. Le Roux, Mine ventilation notes for beginners, 2nd Edition, Published the mine ventilation society of South Africa (Printed by CTP Printers (Transvaal) Limited, 1972)

3. I. Matei, R. Moraru, Environmental Engineering and underground ventilation, (in Romanian) (Technical Publishing House Bucharest, Romania, 2000)

4. W.A. Burgess, M.J. Ellenbecker, R.D. Treitman, Ventilation for control of the work environment, second edition (John Wiley \& Sons, Inc. 2004)

5. ABC Canada, Mine and ventilation products $-\mathrm{ABC}$ Manufacturers of Canada Ltd. 